\title{
KEBIJAKAN AFIRMASI PENDIDIKAN TINGGI UNTUK PAPUA
}

\author{
Ardian Bakhtiar Rivai \\ e-mail: ardian.rivai@ppkn.uad.ac.id
}

\begin{abstract}
ABSTRAK
Sudah jelas bahwa kebijakan afirmasi merupakan dukungan untuk kaum minoritas di negeri ini agar mereka mendapatkan akses terhadap pendidikan. Namun demikian, setelah tahun 2011, Pemerintah Indonesia berupaya untuk meningkatkan jumlah mahasiswa perguruan tinggi dari etnis minoritas dan daerah pinggiran. Salah satu strategi yang dilakukan adalah meningkatkan mahasiswa Papua mengakes pendidikan melalui kebijakan afirmasi di universitas negeri di bawah kementerian pendidikan. Artikel ini menjelaskan tentang bagaimana memahami secara komprehensif kebijakan afirmasi di Indonesia akan lebih baik jika kita bisa mempelajarinya dari pengalaman di perguruan tinggi yang ada di Amerika Serikat yang telah mengaplikasikan kebijakan afirmasi pada perguruan tinggi sejak lama.
\end{abstract}

Kata Kunci: Pendidikan Tinggi, kebijakan pendidikan, kebijakan afirmasi.

\begin{abstract}
It is clear that affirmative action is to support for minority people in the country which to develop their education accesibility. However, after 2011, Indonesian government to have concern to increase the number of higher education student from minority etnic and marginal places. The good one strategy is increase the accessibility of Papua student by affirmative action in public universities under Ministry of Education management. This paper describes that how to understand and aplly the concept of Affirmative Action, especially in Indonesia. To support in comprehensive understand of affirmative action in Indonesia, it is better if we can study from universities in the United States of America expriences which aplly the affirmative action in higher education in a long time ago.
\end{abstract}

Keywords: Higher Education, Educational Policy, Affirmative Action. 


\section{PENDAHULUAN}

\section{Latar Belakang}

Dalam upaya ijtihad kebijakan pendidikan tinggi untuk mengungkap kebijakan afirmasi terhadap mahasiswa Papua, studi ini meyakini beberapa premis terkait logika dan cara kerja kebijakan afirmasi Dikti Kemdikbud. Studi ini meyakini bahwa kebijakan afirmasi memberikan kemudahan akses (access) pendidikan tinggi untuk mahasiswa Papua dalam menjangkau universitas-universitas terbaik di Indonesia. Argumentasi tersebut dibangun atas dasar bahwa kemudahan akses pendidikan tinggi mahasiswa sangat didukung oleh bagaimana sistem admisi yang ada mampu menarik minat, motivasi, dan usaha mahasiswa Papua dalam rangka peningkatan kualitas akademik yang dimilikinya. Ada tiga konsep berfikir yang menjadi pemahaman dalam studi ini.

Pertama, studi ini meyakini bahwa program afirmasi Dikti Kemdikbud menjadi pemicu adanya sistem admisi (admission) pendidikan tinggi di Indonesia yang menganut prinsip-prinsip keadilan dan kesetaraan etnis maupun ras. Argumen ini menjadi penting untuk dikemukakan, karena, tanpa disadari beberapa tahun belakangan telah muncul apa yang disebut sebagai elitisme pendidikan ${ }^{46}$, dimana admisi pendidikan tinggi hanya dimungkinkan untuk mahasiswa dengan golongan ekonomi menengah atas yang sudah mapan dan didukung fasilitas yang cukup.

Alasan Dikti Kemdikbud, memunculkan program afirmasi pendidikan tinggi adalah untuk mengeskalasi ekonomi sosial masyarakat Papua dengan jalur peningkatan kualitas sumber daya manusia. Pendidikan tinggi merupakan satu-satunya pintu gerbang untuk mengantar pemuda papua menjadi masyarakat terdidik yang kelak akan mampu mengembangkan Papua di masa yang akan datang. Semangat Dikti Kemdikbud untuk meningkatkan angka partisipasi kasar pendidikan tinggi di Papua adalah dalam rangka menjawab masalah tentang rendahnya kualitas capaian akademik pemuda Papua.

Kedua, studi ini meyakini bahwa program afirmasi Dikti Kemdikbud merupakan instrumen yang sangat efektif untuk menciptakan lingkungan belajar (learning environtment) kepada individu mahasiswa program afirmasi Papua. Asumsinya, program afirmasi dapat meningkatkan usaha dan motivasi Papua untuk meningkatkan kualitas akademiknya. Rasionalnya,

46 Lihat Haydon, 2010. 
dengan memberikan ruang kepada Mahasiswa Papua menjadi bagian dari kompetisi berkualitas baik, maka secara tidak langsung juga akan menggiring mereka kepada capaian kualitas terbaik di lingkungan akademisnya itu ${ }^{47}$.

Ketiga, studi ini berkeyakinan bahwa program afirmasi Dikti Kemdikbud merupakan cara pemerintah dalam waktu jangka panjang untuk meningkatkan kualitas sumber daya manusia di Papua. Argumen yang dibangun untuk aspek ini, bahwa dengan memberikan akses pendidikan tinggi kepada pemudapemuda Papua maka secara otomatis juga menjadi cara untuk melakukan apa yang disebut sebagai "Vaksinasi Sosial" kepada Papua ${ }^{48}$. Karena, pendidikan tinggi merupakan cara untuk mengubah nasib individu. Pendidikan tinggi merupakan obat sosial secara vertikal, untuk meningkatkan harkat dan martabat kehidupan sosial individu di masyarakat. Cara paling sederhana untuk mengukur ketercapaian tujuan tersebut adalah dengan mengetahui capaian akademis (student achievement) mahasiswa pelaksana program afirmasi Dikti Papua.

\section{TINJAUAN PUSTAKA}

\section{Tujuan Afirmasi Pendidikan Tinggi}

Kuralender \& Felts (2008) menjelaskan bahwa affirmative action di pendidikan tinggi adalah tentang menjamin akses untuk ras atau etnis minoritas agar bisa menduduki kursi di pendidikan tinggi. Affirmative action merupakan alat untuk meningkatkan representasi kelompok minoritas di pendidikan tinggi dan ketidaksetaraan ras. Untuk konteks saat ini, affirmative action memiliki tujuan eksplisit untuk mencapai tujuan dalam upaya mengobati diskriminasi sosial masa lalu dan membuka kesempatan bagi kelompok minoritas tersebut dalam posisi yang setara.

Menurut Conner \& Rabovsky (2011), jaminan akses pendidikan tinggi adalah adanya kesetaraan (equity) dan keberagaman (diversity) di pendidikan tinggi. Konsep kesetaraan (equity) dalam hal ini adalah adanya distribusi sumber daya manusia di masyarakat secara adil. Membuka akses pendidikan tinggi dimaknai sebagai perbaikan kebijakan spesifik yang dirancang untuk membenahi kondisi masa lalu di sebuah kelompok etnis arau ras

47 Lihat Meeuwisse dkk, 2010.

48 Lihat Tienda \& Sullivan, 2010. 
minoritas di masyarakat. DesJardins $(2003)^{49}$ mengidentifikasi ada dua tipe framework untuk justifikasi akses pendidikan tinggi dalam konteks kesetaraan vertikal. Pertama, berkenaan perlakuan isimewa untuk kelompok minoritas, misalnya dengan merancang kebijakan untuk membuka akses pendidikan tinggi kepada mahasiswa yang berasal dari latar belakang kurang beruntung.

Selanjutnya, kedua, DesJardins menjustifikasi akses pendidikan tinggi berkenaan dengan equity intergenerational (kesetaraan lintas generasi), yaitu distribusi sumber daya untuk mendukung kesetaraan antargenerasi yang berbeda. Dalam rangka memformulasikan kebijakan afirmasi untuk membuka akses pendidikan tinggi, Conner \& Rabovsky $^{50}$ menyebutkan ada dua pedoman pokok. Pertama, lingkungan kampus, yaitu menciptakan kehidupan lingkungan belajar akademis (learning environment) yang toleran kepada kelompok minoritas, yang dalam studi ini kelompok minoritas dimaksud adalah mahasiswa Papua. Kedua, capaian akademis, yaitu untuk mengetahui seberapa efektif kebijakan afirmasi mampu memberikan pengaruh dalam upaya pengembangan sumber daya kelompok minoritas untuk mengembangkan kemampuannya di pendidikan tinggi. Capaian akademik ini merupakan tujuan pokok bagi pelaksanaan program afirmasi di pendidikan tinggi ${ }^{51}$.

Connor \& Schwab (2010) menyatakan bahwa pedoman untuk menjustifikasi keterbukaan akses pendidikan tinggi dalam kebijakan afirmasi adalah adanya perlakuan istimewa dalam proses admisi. Perlakuan istimewa yang dimaksudkan adalah dengan mempertimbangkan keberagaman ras, gender, etnis, dan bangsa terhadap student body di univesitas. Pokok penting dari pedoman justifikasi akses pendidikan tinggi oleh Connor \& Schwab (2010) adalah adanya pertimbangan kepada kelompok minoritas untuk berhak menerima perlakuan istimewa dari aspek penerimaan (admission) di sebuah universitas. Tampaknya Connor \& Schwab (2010) agak mengabaikan aspek proses dan capaian akademis di pendidikan tinggi. Karena, menurut Connor \& Schwab (2010), afirmasi dalam penafsirannya adalah cara untuk memasukkan kelompok ras minoritas untuk menjadi bagian dari komunalitas di sebuah pendidikan tinggi. Penekanannya adalah bagaimana admisinya; bukan bagaimana proses dan capaian akademiknya.

49 Dalam Conner \& Rabovsky, 2011.

50 Ibid, 2011.

51 Lihat DesJardins (2003) dalam Conner \& Rabovsky, 2011. 


\section{Menyoal Affirmative Action di Pendidikan Tinggi}

Menurut Libertella, dkk (2007), affirmative action adalah tindakan positif yang langsung bersifat konstruktif dan memberikan perlakuan kemudahan bagi kelompok minoritas. Afirmasi bisa berupa kompensasi atau mendorong kemajuan untuk menciptakan lingkungan yang membuka akses individu dimana ras dan gender bukan lagi menjadi aspek yang menghalangi kemampuan seseorang untuk berkembang. Sedangkan menurut Crosby $(1994)^{52}$, kebijakan afirmasi (affirmative action-policy) adalah kebijakan yang dirancang untuk memastikan kesetaraan kesempatan untuk anggota kelompok yang memiliki sejarah kurang beruntung di sebuah masyarakat.

Menurut Gallaher dkk (2009), affirmative action adalah kebijakan pemerintahan yang bertujuan untuk memperbaiki diskriminasi masif yang diarahkan kepada ras atau etnis minoritas secara spesifik. Affirmative action dalam definisi ini menyediakan prosedur dan pedoman untuk menjamin warga negara yang memenuhi syarat dan kepentingan, tanpa memperhatikan ras, etnis, gender, agama, atau usia. Tujuannya, untuk menciptakan kesetaraan untuk partisipasi di dalam pendidikan tinggi, ketenagakerjaan, pemerintahan, pemukiman, dan isu kesejahteraan sosial lainnya. Menurut Gallaher dkk (2009), affirmative action tidak dibatasi hanya untuk perihal diskriminasi, tetapi juga aspek kesejarahan masa lalu yang menunjukkan adanya ketidaksetaraan. Tujuannya, untuk mendorong menciptakan kesetaraan dengan membuka akses kepada arena publik dan privat.

Diskursus yang berkembang di banyak literatur menunjukkan bahwa affirmative action terfokus kepada perlakuan istimewa kepada kelompok ras atau etnis minoritas. Namun, affirmative action harus difahami berbeda dengan dengan nepotisme, dimana memberikan kemudahan dalam akses pendidikan tinggi bukan didasarkan atas kepentingan minoritas tetapi lebih kepada kepentingan subjektif yang sudah ambisius ${ }^{53}$.

Kurlaender dan Felts (2008) mendefinisikan affirmative action sebagai kebijakan untuk meningkatkan jumlah representasi kelompok minoritas di pendidikan tinggi. Meningkatkan jumlah kelompok ras minoritas dilakukan dengan mengubah sistem admisi universitas yang memberikan kemudahan dan membuka peluang yang lebih besar terhadap kelompok

52 Dalam Libertella dkk, 2007.

53 Lihat Gallaher, dkk, 2009. 
ras minoritas untuk diterima sebagai mahasiswa universitas tersebut. Dasar inilah yang saya gunakan untuk menjelaskan bagaimana kebijakan afirmasi pendidikan tinggi yang dilakukan oleh Dikti Kemdikbud. Karena, untuk konteks ke-Indonesiaan, masyarakat Papua yang tergolong kelompok ras minoritas, faktanya belum mendapatkan akses pendidikan tinggi yang relatif mudah jika dibandingkan dengan kelompokkelompok ras lain di Indonesia. Alasan logis untuk menjelaskan minimnya akses pendidikan tinggi untuk Papua adalah karena memang Papua merupakan daerah yang berada di Terdepan, Terluar, Tertinggal (3T).

Penjelasan legal tentang affirmative action di pendidikan tinggi diargumentasikan oleh Justin Powell pada tahun 1978 dalam amar putusan hakim US Supreme Court yang menyebutkan bahwa institusi pendidikan tinggi dengan menggunakan statuta internalnya bisa memasukkan aspek ras atau etnis untuk mempertimbangkan sistem admisi sebagai cara untuk meningkatkan varietas student body di sebuah universitas $^{54}$. Amar putusan hakim ini merupakan keputusan yang sangat penting, karena sangat efektif untuk melegalisasi tujuan dari kebijakan afirmasi di Amerika Serikat. Yang kemudian menjadi semacam cara mempromosikan konsep perbedaan dalam instansi pendidikan tinggi dan mengidentifikasi bentuk tanggungjawab negara.

\section{Konsep Admisi dalam Afirmasi Pendidikan Tinggi}

Untuk bisa menjastifikasi akses pendidikan yang didorong dari kebijakan afirmasi maka pendekatan paling awal yang digunakan adalah dengan analisis admisi terhadap mahasiswa Papua untuk diterima di universitas yang ditunjuk Kemdikbud. Tienda \& Sullivan (2010) menjelaskan bahwa untuk konteks pendidikan tinggi, affirmative action diidentifikasi dengan adanya akses dengan memegang prinsip bersama antara prinsip demokratis dan keperluan basis sistem penghargaan yang baik. Selain itu, kebijakan affirmative action bisa berhasil apabila diskriminasi bisa dicegah dan ditiadakan.

Lebih lanjut Tienda \& Sullivan (2010) menyatakan bahwa faktor yang paling penting dalam pelaksanaan program afirmasi adalah dengan memasukkan aspek ras atau etnis sebagai pertimbangan penerimaan (admission) mahasiswa di sebuah universitas. Sehingga, affirmative action dalam perkara ini ditafsirkan

54 Lihat Kurlaender dan Felts, 2008. 
sebagai strategi untuk penyetaraan akses untuk seleksi institusi pendidikan tinggi. Pendekatan admission dalam konteks affirmative action merupakan sebuah tindak lanjut konsensus tentang strategi yang bisa diterima semua kalangan sebagai cara untuk memberikan kesempatan yang sama di ranah dunia pendidikan tinggi.

Tienda \& Sullivan (2010) menawarkan tiga alternatif yang bisa digunakan untuk mengusulkan pertimbangan ras dan etnis dalam sistem admission pendidikan tinggi. Pertama, murni kemampuan akademik. Artinya, jika mahasiswa Papua yang memang memiliki kemampuan akademik yang mencukupi prasyarat masuk di Universitas, secara otomatis bisa diterima sebagai mahasiswa dengan label kemampuan akademiknya itu. Meski, universitas yang bersangkutan memang sedang melasanakan program afirmasi. Kedua, faktor kelas sosial, mahasiswa Papua yang bisa diterima dalam proses seleksi masuk dalam konsep ini adalah mereka yang memang berasal dari latar belakang keluarga yang kurang beruntung. Sehingga, affirmative action yang diterapkan kepadanya memiliki misi untuk mengangkat harkat dan taraf hidup dirinya dan keluarganya.

Ketiga, aspek rencana persentase, maksudnya untuk memberikan implikasi perbedaan variasi latar belakang suku bangsa mahasiswa di sebuah universitas. Aspek ini juga bertujuan untuk mendorong adanya keberagaman di kampus. Pendekatan admisi dalam program afirmasi pendidikan tinggi juga dimaknai sebagai penekanan sistemuntukmengakomodir berbagai kelas sosial dan latar belakang budaya di sebuah universitas. Dalam pendekatan ini, memang penggunan hasil skor tes dan kemampuan akademik lainnya, perlu dikesampingkan karena penekanan utamanya justru untuk memberikan ruang kepada mereka para mahasiswa yang berlatarbelakang budaya atau ras maupun etnis minoritas.

\section{Konsep Lingkungan Belajar \\ dalam Afirmasi Pendidikan Tinggi}

Menurut Meeuwisse dkk (2010), lingkungan belajar (learning environment) memberikan pengaruh yang signifikan terhadap pengembangan kemampuan akademik mahasiswa. Dalam pendekatan ini, interaksi mahasiswa dengan dosen, tenaga kependidikan, dan sesama mahasiswa menjadi faktor yang menentukan kesuksesan seorang mahasiswa. Sehingga, dalam proses mengafirmasi mahasiswa Papua untuk bisa mencapai kesuksesan akademik, faktor lingkungan belajar menjadi determinan yang cukup penting. Seiring dengan adanya demokratisasi pendidikan tinggi, faktor lingkungan merupakan aspek pendorong adanya sebuah konsep yang sering disebut dengan "kebebasan akademis". Untuk mengaktualisasikan konsep tersebut, 
maka sudah menjadi keharusan agar kondisi lingkungan akademis yang dibentuk terlebih dahulu ${ }^{55}$.

Konsep lain yang juga menjadi bagian dari pendekatan ini adalah tawaran konsep dari Tinto $(1998)^{56}$ yang menteorisasikan bahwa institusi pendidikan tinggi harus konsisten membangun sistem akademik dan sistem sosial untuk mencapai integrasi sosial yang juga merupakan spirit dari affirmative action pada kalangan ras yang beragam. Dalam pandangan konsep Tinto, lebih lanjut dijelaskan bahwa bentuk integrasi sosial dalam lingkungan akademis merupakan ukuran performance mahasiswa untuk mengembangkan kemampuan intelektualnya selama menempuh pendidikan di Universitas. Itu artinya, sesungguhnya meski secara ukuran kualitas input memiliki perbedaan yang signifikan, apabila selama prosesnya diintegrasikan, ada kecenderungan bahwa hasil output-nya menunjukkan angka kualitas yang tidak terlalu signifikan.

Dalam pendekatan ini sekaligus menganggap bahwa input tidaklah sepenting proses, karena penekanan dalam pendekatan ini adalah bagaimana menciptakan sistem akademik dan sistem sosial untuk mendukung proses perkuliahan yang terintegrasi antara mahasiswa reguler dan mahasiswa afirmasi. Lebih lanjut teori Tinto ini juga menjelaskan perlunya integrasi aspek formal dan informal dalam proses perkuliahan yang integratif. Integrasi akademik sebagai bentuk implementasi aspek formal dapat diukur dengan capaian akademik mahasiswa program afirmasi (student achievement). Namun, faktor hubungan dan interaksi dengan fakultas juga menjadi pendukung dari sisi informal akademisnya ${ }^{57}$.

Zepke $(2006)^{58}$ menjelaskan bahwa terdapat hubungan yang signifikan antara learning environment dan kualitas interaksi untuk membentuk karakter dan menciptakan lingkungan yang kooperatif. Kondisi yang demikian itu membantu mahasiswa untuk mengintegrasikan pengalaman dan hasil studi yang memuaskan. Begitu juga, Braxton $(2000)^{59}$ mengemukakan teori yang sama, bahwa terdapat hubungan yang signifikan antara active learning behaviour di dalam kelas dan integrasi sosial (kelompok belajar dan hubungan di luar kelas) terhadap capaian prestasi akademik mahasiswa.

55 Lihat Meeuwisse dkk, 2010.

56 Ibid, 2010.

57 Ibid, 2010.

58 Ibid, 2010.

59 Ibid, 2010. 
Poin penting yang bisa dipetik dari pendekatan ini yaitu lingkungan belajar (learning environment), baik itu di dalam maupun di luar kelas, merupakan determinasi yang sangat penting untuk menghasilkan learning outcome yang maksimal. Dalam pendekatan ini, lingkungan belajar mampu menstimulasi interaksi sesama mahasiswa, dan mahasiswa-dosen, untuk mengembangkan capaian prestasi akademik secara bersamasama meski berasal dari latar belakang etnis yang beragam ${ }^{60}$.

Studi ini melacak kebermanfaatan kebijakan afirmasi Dikti Kemdikbud untuk mendorong mahasiswa Papua sebagai kelompok etnis minoritas agar dapat menjangkau akses pendidikan tinggi negeri yang ditunjuk oleh Kementerian Pendidikan dan Kebudayaan. Akses pendidikan tinggi yang dimaksudkan dalam studi ini yaitu, perlakuan istimewa dalam proses penerimaan (admission), kondisi lingkungan akademis, dan capaian akademik oleh mahasiswa program afirmasi Kemdikbud.

\section{Model Afirmasi Sektarian:}

\section{Belajar dari Indiana University}

Agar lebih komprehensif dalam memahami afirmasi pendidikan tinggi. Pada bagian ini dijelaskan tentang model-model afirmasi pendidikan tinggi di Amerika Serikat. Ada tiga model yang saya jadikan acuan untuk memahami bagaimana Dikti Kemdikbud menerapkan afirmasi pendidikan tinggi untuk mahasiswa Papua. Model pertama, yaitu model afirmasi sektarian di Indiana University. Dalam kesejarahan affirmative action di dunia, Indiana University termasuk institusi pendidikan tinggi yang mempelopori adanya kebijakan yang afirmatif. Williams (2003) menjelaskan bahwa universitas modern merupakan institusi yang sekuler, namun tetap berpedoman kepada nilai-nilai religius sebagai fondasinya.

Statuta di Indiana University sangat jelas berkomitmen untuk menghapuskan faham sektarian dalam pengelolaan pendidikan tinggi. Andrew Wylie (Presiden pertama Indiana University 1829-1851), seperti dijelaskan oleh Williams (2003), memegang teguh prinsip-prinsip kesetaraan ras dan gender sebagai khitah statuta di Indiana University. Semangat ini sesungguhnya menjadi pintu masuk untuk melaksanakan affirmative action untuk calon-calon mahasiswa dari kelompok ras minoritas di Amerika.

Sisi humanisme pengelolaan pendidikan tinggi di Indiana University menjadi inspirasi besar dalam melakukan studi ini. Karena, pada

60 Untuk penjelasan lebih lengkap, lihat Meeuwisse dkk, 2010. 
hakikatnya semangat untuk melaksanakan kebijakan afirmasi pendidikan tinggi adalah bagaimana memberikan dorongan bagi mereka kelompokkelompok minoritas untuk bisa menikmati pendidikan tinggi seperti layaknya kelompok-kelompok lainnya. Pada poin ini, Williams (2003) mencoba memberikan argumen bahwa sesungguhnya inti dari kebijakan afirmasi adalah bagaimana mempertemukan beragam kelompok suku, agama, ras, sekte, dan sebagainya untuk berinteraksi dan berproses dalam sebuah institusi pendidikan tinggi dalam mencapai tujuan yang dicita-citakan bersama.

\section{Model Afirmasi Identitas Kesukuan: Belajar dari The Ohio State University}

Hal menarik lainnya juga dilakukan di Ohio State University, dimana universitas melakukan kebijakan afirmasi untuk kelompok mahasiswa dari ras Appalachian yang semakin hari semakin luntur identitas aslinya. Sebagai wujud dari program afirmasi identitas asli tersebut, Ohio State University melaksanakan sebuah projek untuk menumbuhkan kembali identitas dan kebanggaan sebagai kelompok ras Appalachian ${ }^{61}$. Ada banyak program yang dilakukan oleh pengelola Ohio State University. Namun, program-program tersebut tetap diawali dengan bagaimana memberikan kemudahan akses untuk bisa masuk di OSU dengan program afirmasi penerimaan mahasiswa baru dari kalangan kelompok Appalachian.

Sebagai tindak lanjut dari sistem admisi yang afirmatif kepada kelompok mahasiswa Appalachians, Ohio State University memberikan afirmasi program untuk membangun identitas mahasiswanya melalui kegiatan dan pendanaan terkait pembangunan karakter Appalachians ${ }^{62}$. Bentuk-bentuk program afirmatif tersebut di antaranya, konseling khusus, tutorial personal, pusat studi Appalachian, pendanaan terkait projek penelitian Appalachians, membangun perpustakaan Appalachians, dan sebuah program yang disebut dengan "Appalachian Awareness Projects", yaitu kegiatan untuk membangun rasa bangga dan kesadaran sebagai ras Appalachian di Ohio State University.

\section{Model Afirmasi Kuota Kelompok Admisi: Belajar dari University of Illinois}

Program afirmasi pendidikan tinggi yang juga menarik untuk dijadikan sebagai inspirasi adalah

61 Lihat Rose dan Vicent, 1984.

62 Ibid, 1984. 
yang berlaku di University of Illinois. Praktek kebijakan afirmasi di University of Illinois dilakukan dengan membagi kelompok-kelompok seleksi calon mahasiswa. Terdapat tiga kelompok seleksi, yakni SCAT (School and College Ability Test), merupakan kelompok seleksi calon mahasiswa yang dilakukan dengan menilai kemampuan prestasi akademik maupun non-akademik sebelum masuk mendaftar di University of Illinois. Kelompok ini merupakan calon mahasiswa pilihan yang memang secara kemampuan, minat, dan bakatnya sudah unggul ${ }^{63}$.

Kelompok seleksi kedua, yaitu calon mahasiswa yang diseleksi tes secara reguler yang memang secara khusus dilakukan oleh universitas untuk menyeleksi masuk calon mahasiswa. Kelompok mahasiswa ini diukur dengan menggunakan standar internal yang berlaku di University of Illinois. Sehingga, kelompok seleksi reguler memang telah memenuhi standar minimum yang berlaku di University of Illinois. Selanjutnya, kelompok ketiga, adalah kelompok seleksimahasiswauntuk melaksanakan program afirmasi, kelompok seleksi afirmasi dikenal dengan program SEOP (Special Educational Oppor- tunities Program). Kelompok SEOP ini memang dikhususkan bagi calon mahasiswa yang secara akses pendidikan tinggi relatif sulit menjangkau. Baik itu akibat faktor biaya maupun faktor kesempatan dan keterjangkauan ${ }^{64}$.

Studi yang dilakukan oleh Bowers (1970) adalah membandingkan capaian prestasi akademik mahasiswa yang diseleksi masuk dari program reguler dengan program SEOP. Hasil perbandingan tersebut kemudian diukur seberapa signifikan perbedaan antara Indeks Prestasi Kumulatif Mahasiswa reguler dengan mahasiswa SEOP. Dari hasil uji komparasi tersebut, ditemukan bahwa ternyata tidak terdapat perbedaan yang signifikan antara mahasiswa reguler dengan mahasiswa SEOP.

Bowers (1970) menarik kesimpulan bahwa memang meski dengan input kualitas yang berbeda, jika dalam prosesnya sama, akan menghasilkan output mahasiswa yang memiliki kualitas tidak terlalu beda secara signifikan. Dari data tersebut, bisa dianalisis bahwa program afirmasi memang menjadi solusi yang tepat untuk memberikan peluang akses pendidikan tinggi untuk calon mahasiswa Papua dalam menjangkau

63 Lihat Bowers, 1970.

64 Ibid, 1970. 
pendidikan tinggi seperti yang sudah diprogramkan oleh Dirjen Dikti Kementrian Pendidikan dan Kebudayaan.

\section{Afirmasi Pendidikan Tinggi di University of California}

Beberapa studi sudah pernah dilakukan terkait bagaimana affrimative action dapat memberikan kontribusi positif terhadap peningkatan akses pendidikan untuk kelompok minoritas. Studi yang paling menarik adalah yang dilakukan oleh Rose (2005), yang mengangkat tema tentang efek program affirmative action di University of California at San Diego. Penelitian yang dilakuan oleh Rose (2005) menggunakan data administrative dari University of California at San Diego. Penelitian yang dilakukan oleh Rose (2005) bertujuan untuk menghimpun pengaruh program afirmasi terhadap grade point average (GPA) atau yang dalam istilah di Indonesia sering disebut sebagai Indeks Prestasi Akademik (IPK).

Salah satu kritik awal saya terhadap penelitian yang dilakukan oleh Rose (2005) ini, yaitu bahwa riset ini tidak melacak secara mendalam bagaimana sistem dan mekanisme admisi, dan bagaimana learning process para peserta program afirmasi di University of California at San Diego. Hal itu sangatlah wajar, karena metode yang digunakan adalah metode kuantitatif, sehingga data dan analisis yang disajikan juga relatif tidak bisa menggambarkan bagaimana gambaran real di lapangan tentang kondisi program afirmasi di University of California at San Diego. Analisis data yang digunakan oleh Rose (2005) adalah analisis regresi dari grade point average (GPA) mahasiswa program afirmasi.

Rose (2005) menjelaskan bahwa Negara Bagian California sejak tahun 1960 sudah menerapkan apa yang disebut sebagai The California Master Plan for Higher Education. Inti dari rencana tersebut masih konsisten diterapkan hingga saat ini, yaitu mandat tentang 12,5\% lulusan terbaik dari high school (di Indonesia setara dengan SMA) di California dapat langsung diterima di salah satu dari delapan kampus di California. Selain menggunakan basis GPA, California juga menerapkan sistem penerimaan calon mahasiswa dengan basis SAT score (Scholastic Aptitude Test) yang dalam istilah ke-Indonesia-an agak mirip dengan tes potensi akademik (TPA) dengan kekhususan kemampuan nalar dan menulis.

Barulah sejak tahun 1990 University of California at San Diego menerapkan konsideran tentang sistem admisi kepada kelompok suatu ras. Affirmative action yang mulai diberlakukan di University of California at San Diego tersebut awalnya menimbulkan pro dan kontra. Perdebatan sejak itu sudah berkutat 
antara mereka para penganut liberalisme dan sosialisme. Hal menarik dari program afirmasi di University of California at San Diego adalah sistem yang dibangun untuk penerimaan mahasiswa baru ${ }^{65}$.

Sistem admisi di University of California at San Diego yang digunakan sangat akomodatif terhadap calon mahasiswa yang memang memiliki kualitas terbaik dan juga tidak mengabaikan kualitas mahasiswa yang kurang, yang berasal dari ras atau kelompok minoritas sebagai peserta program afirmasi. University of California at San Diego membagi calon mahasiswa menjadi 3 kelompok, yaitu Group A, B, dan C dalam sistem admisinya.

Group A adalah mereka para mahasiswa yang diseleksi berdasarkan prestasi akademiknya. Perhitungan prestasi akademik diterapkan dengan sistem Academic Index Score (AIS). Academic Index Score dihitung berdasarkan GPA saat masih di High School, SAT scores, dan pelatihan yang pernah diikuti oleh para calon mahasiswa saat masih menempuh pendidikan jenjang High School. Kemudian, dari lamaran yang masuk akan direngking dan dicari peringkat teratas. Kuota untuk Group A ini sebesar $60 \%$ dari total jumlah mahasiswa di University of California at San Diego ${ }^{66}$.

Kelompok kedua dalam sistem admisi University of California at San Diego, yaitu Group B, disediakan kuota $30 \%$ dari total jumlah keseluruhan mahasiswa per angkatan. Kelompok ini diseleksi berdasarkan mereka para calon mahasiswa yang cukup hanya memenuhi persyaratan masuk di University of California at San Diego. Kelompok mahasiswa Group B boleh tidak memenuhi perhitungan Academic Index Score (AIS). Namun, memiliki rekam jejak akademis yang sangat kuat yang dikombinasikan dengan kualitas personal seperti pengalaman kepemimpinan, bakat yang spesial, dan pengalaman unik lainnya ${ }^{67}$.

Group C, yaitu kelompok ketiga, disediakan kuota sebesar 10\% dari jumlah keseluruhan mahasiswa. Group $\mathrm{C}$ diseleksi dengan sebuah aturan yang disebut sebagai "special admission". Group C ini memiliki sistem admisi yang mengejawantahkan affirmative action di University of California at San Diego. Kelompok ini terdiri dari perwakilan kaum minoritas dan dari kalangan ekonomi bawah. Sehingga, keputusan untuk penerimaan kelompok

65 Lihat Rose, 2005.

66 Ibid, 2005.

67 Ibid, 2005. 
ini didasarkan juga kepada kondisi demografis minoritas. Deskripsi minoritas dalam pemahaman ini yaitu mereka yang berasal dari ras African Americans, Native Americans, dan Mexican Americans.

Meski penerimaannya berdasarkan afirmasi latar belakang kesukuan, namun University of California at San Diego tetap menghitung kriteria akademik dari kelompok ini. Walau mereka yang menempuh jalur masuk di Group C tidak memiliki skor AIS yang tinggi seperti di kelompok A dan B. Hal spesial dari kelompok $\mathrm{C}$ ini, yaitu para komite team seleksi membaca esai dan aplikasi yang dibuat oleh calon mahasiswa group $\mathrm{C}$, yang menjelaskan tentang representasi kondisi tradisional dari para calon mahasiswa. Esai yang dibuat calon mahasiswa juga memuat tentang motivasi dan usaha tentang calon mahasiswa dari kelompok minoritas agar bisa diterima di University of California at San Diego ${ }^{68}$. Adapun postur admisi calon mahasiswa yang melamar dan melakukan registrasi di University of California at San Diego dijelaskan sebagai berikut.
Tabel 1

Data Admisi UCSD

Tahun 1991-1993

(diluar 57. 669 pelamar yang tidak lolos)

\begin{tabular}{lccccc}
\hline & \multicolumn{5}{c}{ Admission group } \\
\cline { 2 - 5 } Category & A & B & C & Other & Total \\
\hline Admissions & 20,426 & 9,144 & 2,793 & 1,139 & 33,502 \\
As percentlage of lotal admissions & 61 & 27 & 8 & 3 & \\
Registrations & 3,672 & 2,811 & 665 & 501 & 7,649 \\
As peccentage of total registrations & 48 & 37 & 9 & 9 & \\
As peccentage of admissions within own group & 18 & 31 & 24 & 44 & \\
\hline
\end{tabular}

Sumber: University of California at San Diego (dalam Rose, 2005)

Hasil studi yang dilakukan Rose (2005) terhadap mahasiswa kelompok afirmasi di University of California at San Diego menemukan ternyata bahwa nilai rata-rata prestasi akademik mahasiswa program afirmasi lebih rendah daripada nilai rata-rata mahasiswa di group A dan group $\mathrm{B}$. Nilai GPA mahasiswa kelompok afirmasi rata-rata 2.88 , sedangkan nilai GPA group B rata-rata 3.08, dan yang tertinggi, nilai rata-rata group $\mathrm{A}$, sebesar 3.29. Perbedaan nilai GPA (grade point average) antara group $\mathrm{C}$ dan B hanya 0.30 point saja ${ }^{69}$.

Namun demikian, selisih GPA antara group B dan C ini relatif kecil, mengingat perbedaan latar belakang mereka saat masih menempuh jenjang

68 Ibid, 2005.

69 Ibid, 2005. 
high school, sehingga pada intinya kehidupan akademis mereka di grade point average tidak terlalu mengkhawatirkan. Seperti dijelaskan oleh Karabel \& Jaquez (2003) $)^{70}$, bahwa perbedaan asal sekolah sangat mempengaruhi prestasi akademik mereka selama di grade point average, selain itu karakteristik latar belakang keluarga, demografis asal, dan latar belakang lain terhadap pribadi siswa program afirmasi cukup berpengaruh signifikan terhadap prestasi akademik mereka. Meski, untuk beberapa kasus juga ada pengecualian tentang prestasi mahasiswa program afirmasi yang menonjol.

Temuan lain dari studi Rose (2005) yaitu bahwa program afirmasi di University of California at San Diego mampu menciptakan lingkungan belajar (learning environment) yang variatif dan akomodatif kepada semua kelompok mahasiswa, baik itu kelompok program afirmasi maupun yang bukan. Sehingga, diskusi yang kemudian muncul untuk pihak universitas dan pemerintah, mahasiswa program afirmasi ternyata tidak memiliki kualitas yang terlalu buruk jika dihitung selisihnya dengan mahasiswa program non-afirmasi. Mahasiswa program afirmasi, dengan kebijakan ini, berpotensi untuk dihasilkan sebagai cara penguatan kewarganegaraan. Sehingga, kesadaran mereka sebagai bagian dari warga California akan melekat dengan kuat. Hasil ini juga yang saya harapkan dalam program afirmasi di Indonesia untuk mahasiswa Papua, bagaimana membangun kesadaran mereka sebagai warga negara Indonesia agar memahami identitasnya sebagai orang Indonesia, juga merupakan bagian dari agenda setting program afirmasi Dikti Kemdikbud.

Pelajaran menarik bisa kita dapatkan dari apa yang terjadi di University of California at San Diego bahwa affirmative action menjadi universitas sebagai ruang yang aksesibel terhadap semua golongan dan kelompok. Universitas menjadi sangat akomodatif kepada semua ras atau etnis sehingga terdapat kekayaan budaya yang terangkum dalam lingkungan belajar (learning environment) yang sudah diciptakan sebagai cara untuk membangun kualitas sumber daya manusia, bukan menghimpun sumber daya manusia yang ada. Indonesia sangat berkewajiban untuk membangun sistem yang sama, sistem dimana pendidikan tinggi yang mampu mengakomodasi semua kelompok dan golongan dalam sebuah lingkungan belajar yang ramah dan berkemanusiaan.

70 Ibid, 2005. 


\section{Pengalaman Menarik dari Harvard University}

Pengalaman menarik lainnya yang bisa dipetik Indonesia untuk menerapkan kebijakan afirmasi saya pelajari dari pengalaman di Harvard University. Harvard punya pengalaman yang lebih panjang daripada UC San Diego. Di Harvard, kebijakan afirmasi sudah mulai diterapkan sejak tahun $1973^{71}$. Kebijakan afirmasi di Harvard awalnya merupakan inisiatif dari Lyndon Johnson's pada tahun 1965. Dalam konsepnya, program afirmasi di Harvard ini mengharuskan adanya ketersediaan (availibility) untuk kelompok perempuan dan minoritas untuk kategori tenaga kerja pada Universitas, seperti di sekretariat, humas, dan bagian-bagian lain. Mekanisme yang dibangun pada awalawal rintisan program afirmasi ini, yaitu untuk memberikan akses kepada kelompok minoritas agar bisa termotivasi untuk mencapai prestasi kerja yang terbaik sesuai kemampuannya masing-masing ${ }^{72}$.

Di era pemerintahan Presiden Reagan, bahkan diberlakukan tentang adanya kewajiban bagi institusi pendidikan tinggi yang terpilih untuk menampung kelompok-kelompok ras minoritas agar bisa menempuh jenjang pendidikan tinggi. Yang menarik adalah, tentang pemberlakuan penghargaan bagi instansi pendidikan tinggi yang mampu menampung kelompok ras minoritas, tidak saja hanya dari aspek kuantitasnya, tetapi lebih daripada itu, aspek kualitas lulusan yang dihasilkan dari program afirmasi di pendidikan tinggi. Dari bangunan sistem program afirmasi era pemerintahan Reagan tersebut, Harvard termasuk universitas yang sukses meraih penghargaan sebagai instansi pendidikan tinggi yang melaksanakan program afirmasi pendidikan tinggi ${ }^{73}$.

Dari hasil laporan The Office for Civil Rights ${ }^{74}$, dijelaskan bahwa Harvard merupakan universitas yang paling konsisten menjalankan program afirmasi di Amerika Serikat. Misalnya, Harvard menjadi institusi pendidikan tinggi yang mempelopori gerakan perlawanan terhadap diskriminasi rasial termasuk juga terhadap pelamar dari Asia. Kemajuan sangat pesat dalam hal admisi di Harvard ditunjukkan dari peningkatan jumlah penerimaan mahasiswa dari kelompok minoritas dari tahun 1980 hingga tahun 1990. Tercatat, pada tahun 1980 program afirmasi untuk penerimaan mahasiswa kelompok minoritas di Harvard sebanyak 13\% meningkat menjadi $20 \%$ di tahun $1990^{75}$.

71 Lihat Williams, 1992.

72 Ibid 1992.

73 Ibid, 1992.

74 Ibid, 1992.

75 Ibid, 1992. 


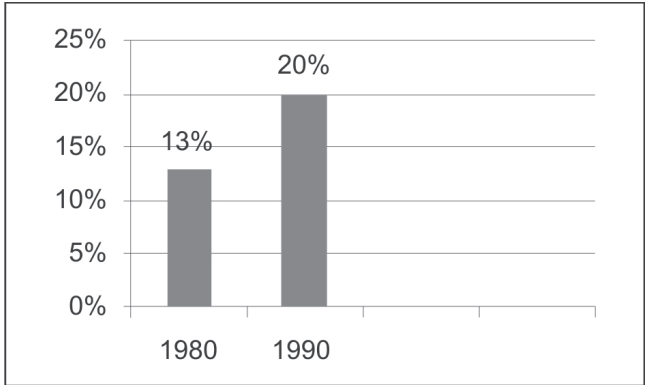

Grafik 1 Perkembangan Jumlah Penerimaan Program Afirmasi di Harvard 1980-1990 (dalam Williams, 1992)

Pada tahun 1985, Harvard baru memulai program afirmasi untuk Medical School, karena pada masamasa awal masih mempersiapkan bagaimana sistem dan mekanismenya. Program afirmasi yang secara khusus melibatkan mahasiswa dari ras African American dan Asian American diterapkan juga di fakultas hukum. Perkembangan admisi untuk melaksanakan program afirmasi di Harvard terus mengalami peningkatan dari tahun 1980, 1985, hingga ke tahun 1990. Peningkatan ini khusus tercatat untuk kelompok mahasiswa dari African American dan Asian American. Rata-rata persentasenya, pada tahun 1980 sebanyak 9\%, meningkat pada tahun 1985 menjadi 10,9\%, dan pada tahun 1990 menjadi $14,8 \%{ }^{76}$.
Tabel 2 Persentase Mahasiswa

African American \& Asian American di Harvard Tahun 1980, 1985,1990

\begin{tabular}{|c|c|c|c|c|c|c|}
\hline \multirow[b]{3}{*}{ Faculty } & \multicolumn{6}{|c|}{ Percentage of Students Who Were } \\
\hline & \multicolumn{3}{|c|}{ African American } & \multicolumn{3}{|c|}{ Asian American } \\
\hline & 1980 & 1985 & 1990 & 1980 & 1985 & 1990 \\
\hline College & 6.8 & 6.0 & 7.7 & 4.7 & 8.9 & 14.8 \\
\hline Graduate school & 2.0 & 1.9 & 2.3 & 2.1 & 2.6 & 3.6 \\
\hline Business & 3.9 & 5.0 & 6.1 & 1.6 & 2.4 & 3.7 \\
\hline Law & 7.4 & 9.5 & 10.4 & 1.9 & 2.6 & 5.8 \\
\hline Medicine & 10.5 & 8.3 & 7.8 & 4.8 & 9.2 & 19.7 \\
\hline Total university & 5.7 & 5.3 & 6.0 & 3.3 & 5.6 & 8.8 \\
\hline
\end{tabular}

Sumber: Harvard University, Office of Budgets, 1991 (dalam Williams, 1992)

Sistem yang dibangun dalam program afirmasi di Harvard dikenal dengan istilah Central Administration. Yaitu, adanya pelayanan terpusat terkait admisi di Harvard untuk melaksanakan program afirmasi bagi kelompok ras minoritas. Namun demikian, pengambilan keputusannya tetap terdesentralisasi, dimana setiap fakultas penerima yang berhak menyatakan lolos atau tidaknya seseorang pelamar yang mendaftar di Harvard. Fokus pelaksanaan dan pengembangan program afirmasi di Harvard ini dilakukan di sepuluh fakultas dan enam divisi akademik untuk mengeliminasi dan meningkatkan promosi program afirmasi bagi kelompok minoritas ${ }^{77}$. 
Kesepuluh fakultas yang menjadi fokus pengembangan program afirmasi di Harvard University, yaitu Faculty of Arts and Sciences; the Graduate Schools of Business Administration, Design, and Education; the Schools of Dental Medicine and Public Health; the John F. Kennedy School of Government; dan the Divinity, Law, and Medical Schools. Sedangkan divisi-divisi yang diintensifkan untuk mengembangkan program afirmasi, yaitu vice presidentsfor administration, alumni affairs, finance, government, and legal affairs, dan President's Office ${ }^{78}$.

Ciri khas dari program afirmasi di Harvard adalah adanya penguatan sistem untuk melaksanakan program afirmasi secara terpadu. Fakultas dan unit administrasi sudah terbangun sistem yang terpadu dalam pelaksanaan program afirmasi. Harvard fokus untuk mengumpulkan dan mengembangkan pelamar program afirmasi yang potensial untuk mendapat jatah kursi kuliah. Setiap dekan dan supervisor memiliki strategi tambahan masingmasing untuk melaksanakan program afirmasi yang terpadu ${ }^{79}$.

Komite pelaksana program afirmasi juga diorganisir oleh anggota komite dari beragam etnis dan gender. Sehingga, pelaksanaan program afirmasi tidak saja hanya untuk mahasiswa tetapi juga staf akademik yang melakukan organisir untuk program afirmasitersebut. Di level internasional, reputasi Harvard memang sudah terkenal memiliki kualitas sistem administrasi yang sangat baik, semua program memang dipersiapkan dengan sangat matang, dibangun, dan diterapkan sesuai dengan prosedur yang sudah ada. Sehingga, tidak mengherankan apabila kesuksesan program afirmasi di Harvard berhasil menghasilkan keluaran mahasiswa minoritas yang berkualitas dan sesuai dengan target capaian universitas. Alasan itu pula yang melandasi saya untuk memasukkan Harvard University sebagai literatur pedoman pelaksanaan program afirmasi di Indonesia.

Dilema yang dialami Harvard dalam melaksanakan program afirmasi yaitu untuk merekonsiliasi kepentingan untuk mencapai kualitas tinggi universitas dengan menerima mahasiswa minoritas kualitas kurang. Sehingga, di satu sisi menuntut adanya peningkatan kualitas yang baik, namun di sisi lain juga menerima in-out mahasiswa berkualitas kurang. Itulah sebabnya untuk mendukung program

78 Ibid, 1992.

79 Ibid, 1992. 
afirmasi ini, membutuhkan energi yang cukup dan respon kebijakan yang sangat sulit ${ }^{80}$. Untuk mengakomodasi dua kepentingan tersebut, maka digunakanlah sistem kuota agar bisa menjalankan dua kepentingan secara bersamaan.

Pelaksanaan program afirmasi berdasarkan pengalaman di Harvard University sekaligus memberikan hikmah kepada kita, bahwa program afirmasi mampu meminimalisir stigma tentang pendidikan yang tidak setara, kesempatan, motivasi yang rendah, semua persepsi buruk tentang kondisi pendidikan tinggi Amerika telah berhasil dihapuskan oleh pelaksanaan program afirmasi di Harvard University $^{81}$. Pada akhirnya, kekuatan manajemen pendidikan tinggi di Harvard untuk melaksanakan program afirmasi ada dalam sistem. Harvard sangat konsisten untuk melaksanakan program desentralisasi dengan menguatkan peran setiap fakultas sebagai pihak yang memiliki kuasa penuh menentukan calon mahasiswa program afirmasi yang akan diterimanya. Namun demikian, desentralisasi tersebut tetap berada di bawah naungan payung universitas, sehingga koordinasi dan konsolidasi kebijakan tetap terlaksana dengan baik.

\section{Penutup}

Dalam melaksanakan afirmasi pendidikan tinggi di Indonesia oleh Dirjen Dikti Kementerian Pendidikan dan Kebudayaan, model yang digunakan adalah model etnis kedaerahan. Maksudnya, afirmasi yang sedang dilakukan oleh Dirjen Dikti Kemdikbud ialah dengan menjaring mahasiswa yang berasal dari daerah tertinggal, terdepan, dan terbelakang. Dalam proses seleksi dan rekrutmen dilakukan bekerja-sama dengan pemerintah daerah tingkat kabupaten yang ada di Provinsi Papua dan Papua Barat. Dalam melaksanakan seleksi ada yang melalui jalur ujian tulis, tes potensi akademik, penilaian rapot saat SMA, dan ada yang diterima dengan jalur prestasi non akademik seperti atlet olahraga.

Apa yang dilakukan oleh Dikti Kemdikbud tentang seleksi model identitas etnis calon mahasiswa yang berasal dari Papua, sesungguhnya memiliki kemiripan dengan model yang diterapkan di University of Illinois. Afirmasi yang dilakukan oleh Dikti Kemdikbud dengan membawa misi untuk meningkatkan kualitas sumber daya manusia Papua yang saat penelitian ini relatif masih sangat tertinggal. Begitu juga dengan yang

80 Ibid, 1992.

81 Ibid, 1992. 
dilakukan di University of Illinois bertujuan untuk meningkatkan kesadaran identitas Appalachian sebagai pembentukan karakter asli suku Appalachian di Amerika Serikat.

Tujuan afirmasi pendidikan tinggi yang dilakukan Kementerian Pendidikan dan Kebudayaan adalah untuk meningkatkan partisipasi pemuda Papua dalam melanjutkan studi ke jenjang sarjana. Program ini juga merupakan bentuk kepedulian pemerintah Republik Indonesia dalam menjawab tantangan tentang rendahnya mutu sumber daya manusia di Papua. Sehingga, diharapkan dengan dilaksanakannya program afirmasi pendidikan tinggi untuk mahasiswa Papua, maka kelak akan dapat menghasilkan sarjana-sarjana bermutu yang memiliki kompetensi akademik yang setara dengan sarjana lainnya di Indonesia.

Afirmasi pendidikan tinggi yang dilakukan oleh Kemdikbud juga bertujuan untuk membangun karakter pemuda Papua. Karakter yang dimaksudkan adalah sebagai cara untuk menangkal faham separatis yang menentang konsep Negara Kesatuan Republik Indonesia. Cara afirmasi ini relatif dipandang cukup relevan digunakan, karena ketika pemudapemuda Papua merantau dan menghadapi habit yang berbeda, selain untuk membangun iklim kompetisi yang variatif juga untuk membangun kesadaran tentang wawasan nusantara di setiap benak pemikiran mereka.
Ketika pemuda Papua telah terbiasa bergaul dengan pemuda-pemuda lain di Indonesia maka wawasanya pun akan terbangun sebagai bentuk kesadaran bagian dari bangsa Indonesia.

Hasil evaluasi yang pernah dilakukan oleh Direktorat Jenderal Pendidikan Tinggi Kemdikbud di Universitas Udayana dan Universitas Pendidikan Ganesha menunjukkan bahwa memang kualitas input mahasiswa yang berasal dari Papua relatif lebih rendah jika dibandingkan calon mahasiswa lain yang diterima secara reguler. Sehingga, dalam konsep tata kelola pendidikan tinggi, bisa disimpulkan bahwa ketika kualitas input tidak optimal, maka dalam tahapan proses harus lebih ekstra dimaksimalkan agar dapat memperoleh output yang optimal. Dalam pemahaman itu jelaslah bahwa kondisi pengelolaan afirmasi pendidikan tinggi di Bali saat ini dan daerah lainnya di universitas penyelenggara afirmasi memang harus meningkatkan kinerja di tahapan proses agar dapat menghasilkan output mahasiswa afirmasi yang optimal.

Apa yang dilakukan oleh Dikti Kemdikbud dalam melaksanakan afirmasi pendidikan tinggi sesungguhnya bentuk implementasi dari apa yang disampaikan oleh Flores dan Oseguera (2013) yang menyatakan bahwa afirmasi pendidikan tinggi merupakan bentuk intervensi pemerintah dalam menyetarakan akses 
pendidikan tinggi terhadap suatu kelompok masyarakat. Model afirmasi yang digunakan oleh Dikti Kemdikbud menjelaskan tentang model kemudahan admisi yang sekaligus memberikan bantuan pendanaan di bawah pengelolaan sebuah universitas (Flores dan Oseguera, 2013). Seperti yang telah dilaksanakan di semua universitas penyelenggara afirmasi pendidikan tinggi di Indonesia, memang kenyataannya universitas penyelenggara afirmasi sekaligus juga menjadi pengelola yang menyalurkan bantuan pendanaan studi kepada mahasiswa Papua. Sehingga, ukuran proses implementasi dan evaluasinya bisa lebih komprehensif dilakukan.

Pada akhirnya, implementasi program afirmasi pendidikan tinggi relatif sudah bisa menjadi gambaran tentang banyak konsep afirmasi yang pernah ditawarkan oleh beberapa ahli, bahwa model afirmasi pendidikan tinggi oleh Kemdikbud menjadi semacam eskalasi bagian pemuda Papua untuk bisa mendapatkan akses pendidikan tinggi yang layak dan menjadi momentum untuk meningkatkan kualitas sumber daya manusia Papua dalam mencapai citacita konstitusi Republik Indonesia.

\section{Daftar Pustaka}

Bowers, John. 1970. The Comparison of GPA Regression Equations for Regularly Admitted and Disadvantaged Freshmen at the
University of Illinois. Source: Journal of Educational Measurement, Vol. 7, No. 4 (Winter, 1970), pp. 219225. Published by: National Council on Measurement in Education. Stable URL: http://www.jstor.org/ stable/1434462.

Cannor, Nancy. \& Schwab, Thomas, Jo. 2010. Affirmative Action and Higher Education in the United States and South Africa. Dalam The Next 25 Years Affirmative Action in Higher Education in the United States and South Africa. Editor David L. Featherman, Martin Hall, dan Marvin Krislov. The University of Michigan Press. Michigan.

Conner, Thaddieus W. \& Rabovsky, Thomas M. Accountability, Affordability, Access: A Review of the Recent Trends in Higher Education Policy Research. The Policy Studies Journal, Vol. 39, No. S1. 2011. Published by Wiley Periodicals, Inc., 350 Main Strees, malden, MA 02148, USA.

Flores, Stella M. \& Oseguera, Leticia. 2013. Public Policy and Higher Education Attainment in a TwentyFirst-Century Racial Demography: Examining Research from Early Childhood to the Labor Market. Dalam Higher Education: Handbook of Theory and Research. Editor Michael B. Paulsen. Springer. New York.

Gallaher, Eboni M. Zamani. Green, Denise O’Neil. Brown II, M Christopher. \& Stovall, David O. 2009. The Case for Affirmative action on Campus: Concepts of Equity, Considerations 
for Practice. Stylus Publishing. Virginia.

Haydon, Graham. 2010. Meritocracy. Dalam Educational Equality. edited by Graham Haydon. Continuum International Publishing Group. London.

Kurlaender, Michal. \& Felts, Erika. 2008. Bakke Beyond College Access: Investigating Racial/Ethnic Differences in College Completion. Dalam Realizing Bakke's Legacy: Affirmative action, Equal Opportunity, and Access to Higher Education. Editedy by: Patricia Martin \& Catherine L. Horn. Stylus Publisihing. Virginia.

Libertella, Anthony F. Sora, Sebastian A. Natale. \& Samuel M. 2007. Affirmative action Policy and Changing. Views. Source: Journal of Business Ethics, Vol. 74, No. 1 (Aug., 2007), pp. 65-71. Published by: Springer. Stable URL: http:// www.jstor.org/stable/25075444

Meeuwisse, Marieke. Severiens, Sabine E. \& Born, Marise Ph. 2010. Learning Environment, Interaction, Sense of Belonging and Study Success in Ethnically Diverse Student Groups. Source: Research in Higher Education, Vol. 51, No. 6 (SEPTEMBER 2010), pp. 528-545. Published by: Springer. Stable URL: http://www.jstor.org/ stable/40785093

Rose, Heather. 2005. The Effects of Affirmative Action Programs: Evidence from the University of California at San Diego. Source: Educational Evaluation and Policy
Analysis, Vol. 27, No. 3 (Autumn, 2005), pp. 263-289. Published by: American Educational Research Association. Stable URL: http:// www.jstor.org/stable/3699572

Rose, Norman R. \& Vicent, Bettye A. Pfau. 1984. Appalachian Identity at Ohio State University. Source: Appalachian Journal, Vol. 12, No. 1 (FALL 1984), pp. 73-78. Published by: Appalachian Journal \& Appalachian State University. Stable URL: http://www.jstor.org/ $\underline{\text { stable/40932632 }}$

Tienda, Marta. \& Sullivan, Teresa A. 2010. The Promise and Peril of the Texas Uniform Admission Law. Dalam The Next Twenty-five Years: Affirmative action in Higher Education in the United States and South Africa. Editor: David L. Featherman, Martin Hall, \& marvin Krislov. The University of Michigan Press. Michigan.

Williams, Gayle. 2003. Andrew Wylie and Religion at Indiana University, 1824-1851: Nonsectarianism and Democracy. Source: Indiana Magazine of History, Vol. 99, No. 1 (March 2003), pp. 2-24. Published by: Trustees of Indiana University. Stable URL: http://www.jstor.org/ $\underline{\text { stable/27792441 }}$

Williams, John B. 1992. Affirmative action at Harvard. Source: Annals of the American Academy of Political and Social Science, Vol. 523, Affirmative action Revisited (Sep., 1992), pp. 207-220. Published by: Sage Publications, Inc.in association with the American Academy of Political and Social Science. Stable URL: http://www.jstor.org/stable/1047592 